\title{
Ageing and Urbanization: Can Cities be Designed to Foster Active Ageing?
}

\author{
John R Beard, MBBS, $\mathrm{PhD}^{1}$ \\ Charles Petitot, MD, $\mathrm{MPH}^{1}$
}

\begin{abstract}
The world is currently experiencing two major demographic transitions: the ageing of populations, particularly in low and middle income countries, and urbanization. This paper briefly summarizes current theories on how the urban environment may influence the health and quality of life of an older person, reviews epidemiologic studies that have investigated this relationship, and highlights urban initiatives that foster active and healthy ageing.

The review identified an extensive body of research consistent with an association between the health of an older person and the physical, social and economic environment in which they live. However, most research in this field has been cross-sectional, and interpretation has been difficult due to numerous methodological limitations, particularly the risk of social selection biases.

More recently, a growing number of longitudinal studies have identified associations consistent with previous cross-sectional research, adding weight to these findings. In the last two years alone, at least thirteen new longitudinal studies examining these issues have been reported, with ten having positive findings. Unfortunately, few of these studies can yet point to specific pathways that may be amenable to intervention.

Concurrent with this research, a number of sizable programmes have been developed to make urban environments more supportive of older people. Both theory and the epidemiologic evidence appear to justify the optimism of these initiatives, although little evaluation has yet been undertaken of their impact.
\end{abstract}

Key words: Ageing, neighbourhood, urban, socioeconomic

Recommended Citation: Beard JR, Petitot C. Ageing and Urbanization: Can Cities be Designed to Foster Active Ageing? Public Health Reviews. 2010;32:427-50.

\footnotetext{
${ }^{1}$ Department of Ageing and Life Course, World Health Organization, Geneva.
}

Corresponding Author Contact Information: John R. Beard at beardj@who.int; World Health Organization, 20, Avenue Appia, CH-1211, Geneva 27, Switzerland. 


\section{BACKGROUND}

Populations around the world are rapidly ageing. By 2050, the global population of people aged 60 years and over is expected to reach almost two billion, with the proportion of older people doubling between 2006 and 2050. ${ }^{1}$ Less developed countries will experience the most dramatic change, and by mid-century approximately 80 percent of older people will live in what are now low or middle income countries.

Some analysts and commentators have suggested that these demographic shifts will place a major burden on health and social systems. ${ }^{2}$ One way of quantifying this is the "old age dependency ratio" which measures the proportion of people aged 65 and over per 100 persons of working age. In Japan, currently the country with the highest life expectancy, this ratio will have increased almost tenfold by 2050 compared to $1950 .{ }^{3}$ While it is tempting to think Japan has already completed the transition to an older population, more than half of this increase has yet to occur.

However, this negative perspective on ageing populations is based on an assumption that older people are inevitably dependent and a burden on society. If older people can maintain their health until the last years of life, and if they live in an environment that allows their ongoing productive engagement in society, ageing populations might instead be considered an overlooked societal resource.

In recent years, there has been mounting interest in the role the urban environment may play in achieving these more positive goals. In part, this reflects new theoretical models, the availability of new analytical methods ${ }^{4,5}$ and awareness that older adults may be more sensitive to urban characteristics such as safety and urban form. ${ }^{6}$ But it has also arisen in response to another major demographic trend that is occurring alongside population ageing: urbanization. In 2008, for the first time, the majority of the world's population lived in cities, and this transition from rural to urban living is expected to continue. ${ }^{7}$

These two demographic trends are not unrelated. By 2050, it is expected that a quarter of urban populations in less developed countries will be over the age of 60 years. In developed countries, 80 percent of older people already live in urban areas. ${ }^{7}$

This paper briefly summarizes current theories on how the urban environment may influence ageing, reviews major population based epidemiologic studies that have investigated this relationship, and provides examples of urban initiatives that have been put in place to make cities more supportive of older people. 


\section{THEORETICAL MODELS}

Many different urban characteristics have been proposed as possible determinants of an equally wide array of health outcomes at all ages. The specific mechanism behind each of these associations is likely to vary, but a number of basic theories have been proposed.

Most attention has been given to the influence of neighbourhood socioeconomic disadvantage (as distinct from household or individual socioeconomic disadvantage). Whether this has been entirely theory driven, or whether it simply reflects the ready availability of neighbourhood socioeconomic data from secondary sources such as census data, is not clear. However, a number of related theoretical models have been developed to explain the frequently observed association between an older person's health and the socioeconomic status of their neighbourhood of residence.

Both the "differential vulnerability" hypothesis and social stress theory posit that disadvantaged neighbourhoods can influence health by directly increasing the likelihood of experiencing personal stress events such as trauma or unemployment. ${ }^{8}$ Physical conditions such as urban decay, physical disorder, and high levels of crime may generate more chronic levels of stress and fear., ${ }^{9,10}$

Neighbourhood disadvantage might also be associated with higher levels of social disorder, ${ }^{11,12}$ lower social cohesion and less informal social control over problem behaviours. ${ }^{9}$ These, in turn, may impede the development of the social networks that may buffer individuals from the stressors they face on a daily basis. ${ }^{13}$ Disadvantaged neighbourhoods may also be less likely to offer other resources such as healthcare facilities, and access to healthy foods. Prevailing cultural norms may steer residents to unhealthy, or in some cases healthy, behaviors and outcomes. ${ }^{14}$

On the other hand, a positive residential environment may provide social resources that buffer the impact of life stressors, ${ }^{15-17}$ present readily accessible and affordable nutritional food that makes it easier for older people to eat a healthy diet, or contain physical characteristics such as trees and parks that foster a sense of well-being and provide a recuperative environment that supports resilience. Good street design, access to public transport and diverse retail outlets may encourage individuals to remain engaged with their local community and maintain supportive social networks. Such features may also encourage walking and other physical activity, ${ }^{18-21}$ which may exert protective effects by strengthening the physiological systems of older adults and reducing functional limitation (e.g., from osteoarthritis).

These causative models complement the theoretical underpinnings of a number of interventions to establish communities that are more conducive 
to "active ageing" and "ageing in place". These arise from an ecological perspective of ageing that assumes an interplay between an individual's functional capacity, adaptation, and their physical and social environment. ${ }^{22}$ They link to related concepts of urban design and service planning for disability and ageing services, including universal design, accessibility, healthy cities, livable communities, and walkable communities. ${ }^{23,24}$ While distinct in their emphases, these generally share the common goal of addressing needs related to health (e.g., accessible and affordable health and healthcare services, opportunities to stay active), participation (e.g., accessible public transportation, information services, recreational programmes, social connections, volunteer opportunities, places to worship, a sense of being valued and respected), and security (e.g., home and community safety, transportation safety, financial security, affordable housing and services).

\section{RECENT RESEARCH}

\section{Methods}

To examine the current evidence for these dynamics, we undertook a structured review of recent analytical epidemiologic literature.

Articles for possible inclusion were identified through a MEDLINE Ovid search (Figure 1). We searched for articles published from January 1, 2000 to December 31, 2009, including the following key words in the title or abstract field:

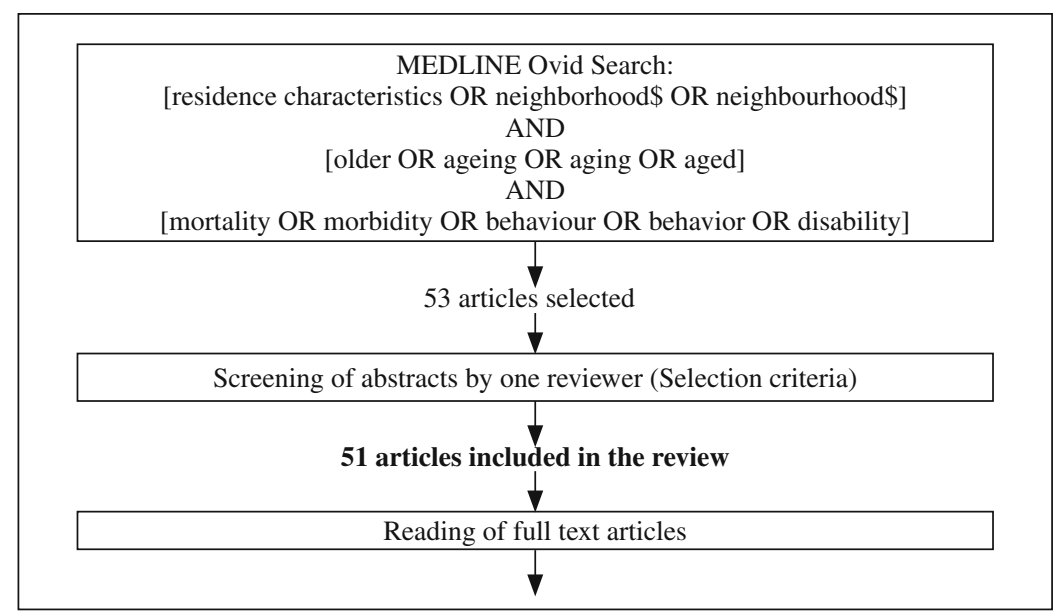

Fig. 1. Flow chart of article selection 
The search identified 2,292 articles. The abstracts of these were reviewed by one reviewer according to the following inclusion and exclusion criteria that had been decided prior to assessing the abstracts: English language empirical population based studies of physical and mental health outcomes (including health behaviours). We excluded from this selection articles in which neighbourhood was not the primary exposure variable or a key variable within an ecologic framework; where neighbourhood had not been defined at a small-area level (e.g., comparing rural and urban); or minimum age of the study population was not [ $>$ or $=$ ] 45 . If it could not be determined from the abstract whether or not the article met all selection criteria, the article was accepted for further review. Fifty-three articles were reviewed in full. Any cited papers that met study criteria but that had not been identified by the original search were also included in the review. A total of 51 articles were finally identified. Longitudinal studies with study populations of greater than 250 are shown in Table 1 (following pages).

\section{Summary of epidemiologic evidence}

Most of the studies reviewed suffer from significant methodological limitations that need to be borne in mind when considering their findings. Foremost amongst these is the cross-sectional nature of most research. Many positive studies had difficulty excluding the possibility that observed relationships resulted from social selection, a tendency for individuals sharing certain characteristics, for example a specific cultural background, to live in similar neighbourhoods. ${ }^{45}$ If social selections were operating, an observed association between living in these neighbourhoods and an outcome of interest may simply reflect this shared cultural heritage of residents, rather than being a consequence of living in that community. Of course, both mechanisms may be at play, further complicating any analysis.

Multilevel studies, which account for key individual level information on participants address some of the concerns about social selection through adjustment for many of the characteristics associated with it (e.g., race, individual socioeconomic status and ethnicity). However, it is very difficult for any cross-sectional study to confidently determine the direction of observed associations. Thus, for example, while high rates of depression and morbidity have been frequently linked with residing in a socioeconomically disadvantaged area, both poor physical and mental health can lead directly to individual economic disadvantage. Since this increases the risk that such individuals will live in disadvantaged neighbourhoods, the reported cross-sectional associations between health and neighbourhood disadvantage may be a consequence of poor health rather than a cause. 


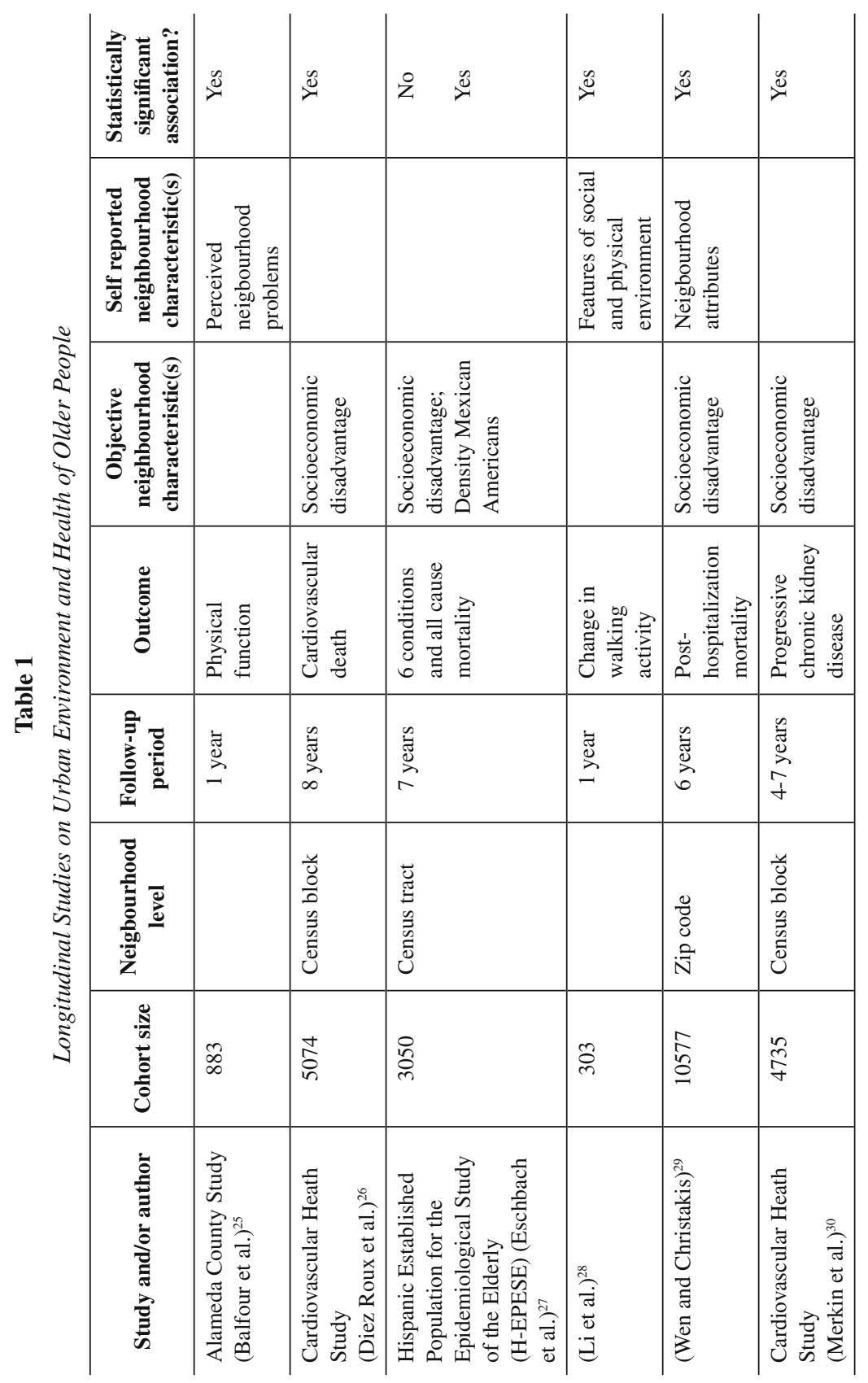




\begin{tabular}{|c|c|c|c|c|c|}
\hline 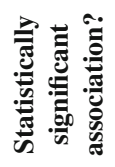 & $\stackrel{0}{\nu}$ & $\stackrel{0}{2}$ & $\triangleq$ & $\stackrel{2}{2}$ z & $\stackrel{\infty}{\infty}$ \\
\hline 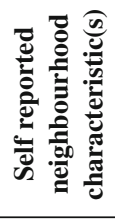 & & & & & \\
\hline 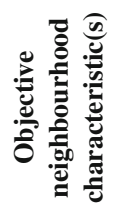 & 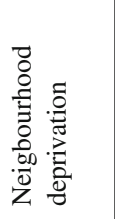 & 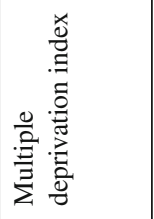 & 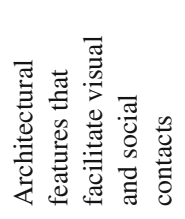 & 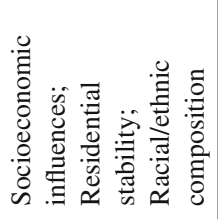 & 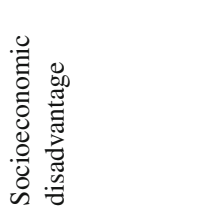 \\
\hline 节 & 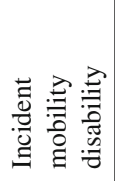 & 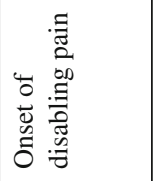 & 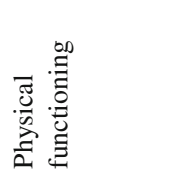 & 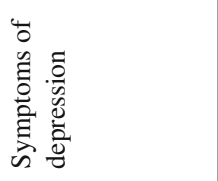 & 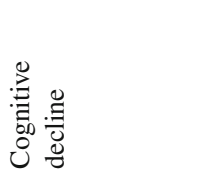 \\
\hline 章 & $\begin{array}{c}\stackrel{0}{\Delta} \\
\stackrel{\sim}{\sim}\end{array}$ & 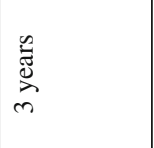 & 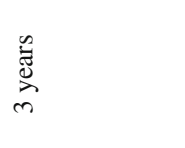 & 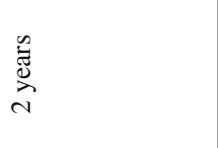 & 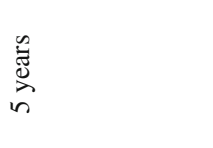 \\
\hline 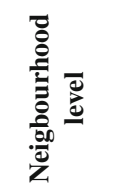 & 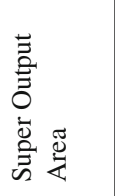 & 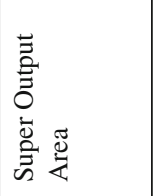 & $\frac{\frac{y}{0}}{\frac{0}{n}}$ & $\begin{array}{l}\overrightarrow{0} \\
\stackrel{\Xi}{\Xi} \\
0 \\
\overline{0} \\
0\end{array}$ & 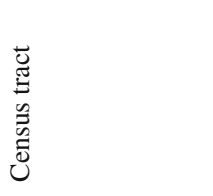 \\
\hline 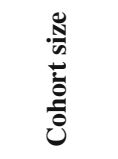 & $\stackrel{\infty}{\underset{+}{+}}$ & 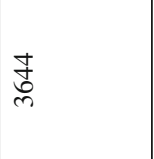 & $\stackrel{\sim}{\sim}$ & $\stackrel{2}{2}$ & ஜి \\
\hline 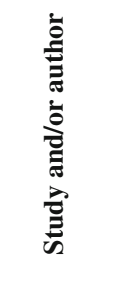 & 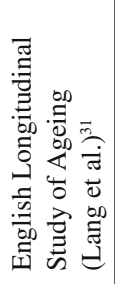 & 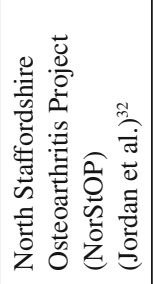 & 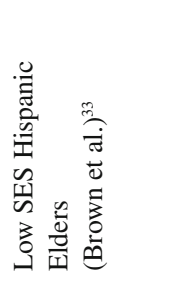 & 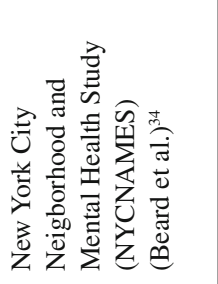 & 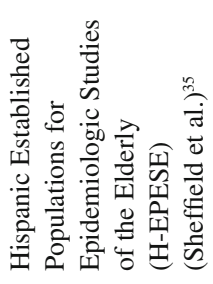 \\
\hline
\end{tabular}




\begin{tabular}{|c|c|c|c|c|c|c|}
\hline 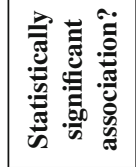 & 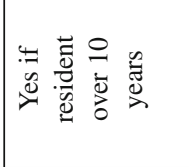 & $\dot{z}$ & $\triangleq$ & 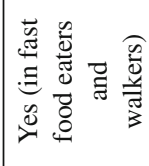 & $\triangleq$ & $\stackrel{\circ}{2}$ \\
\hline 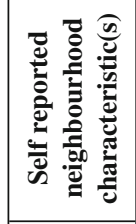 & & & 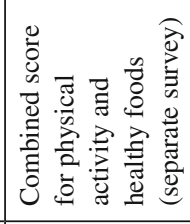 & & & \\
\hline 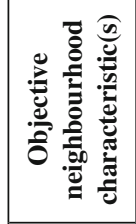 & 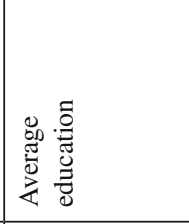 & 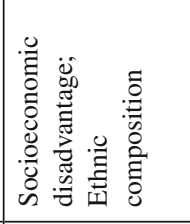 & & 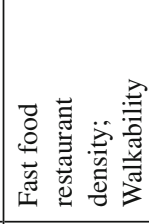 & 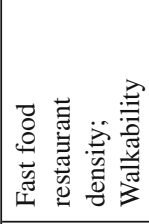 & 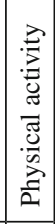 \\
\hline 气ँّ & 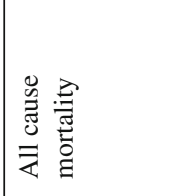 & 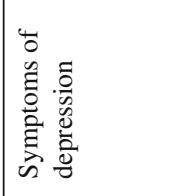 & 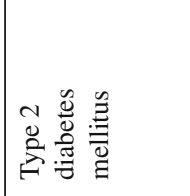 & 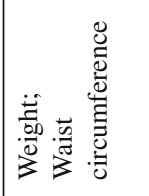 & 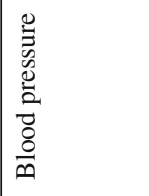 & 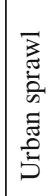 \\
\hline 言 & 怘 & 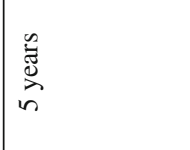 & 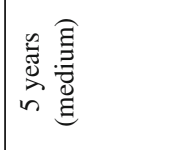 & $\stackrel{\vec{\Xi}}{\stackrel{\Xi}{\Xi}}$ & 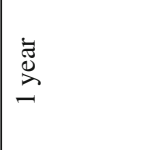 & 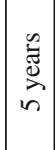 \\
\hline 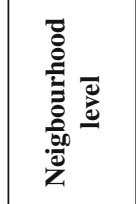 & 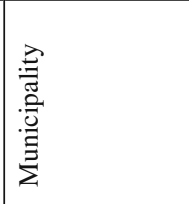 & 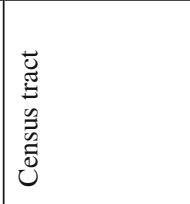 & 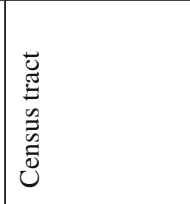 & 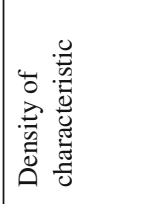 & 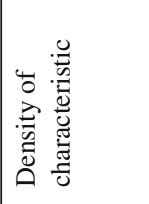 & \begin{tabular}{|c|}
$\vec{a}$ \\
$\vdots$ \\
0 \\
0
\end{tabular} \\
\hline 这 & 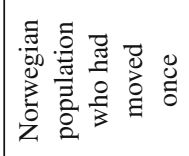 & $\underset{m}{\mathbb{f}}$ & $\begin{array}{l}n \\
\text { సి } \\
\text { ปे }\end{array}$ & $\stackrel{\text { q }}{\Xi}$ & $\stackrel{\stackrel{\text { fo }}{\Xi}}{=}$ & 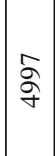 \\
\hline 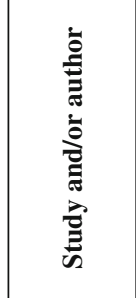 & 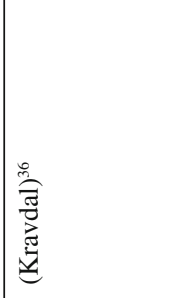 & 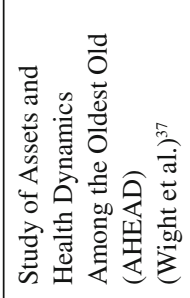 & 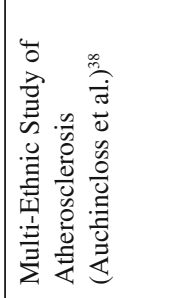 & 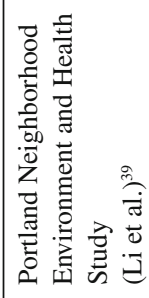 & 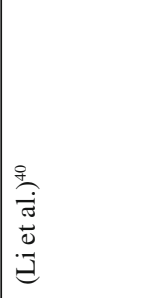 & 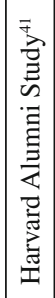 \\
\hline
\end{tabular}




\begin{tabular}{|c|c|c|c|}
\hline 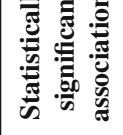 & 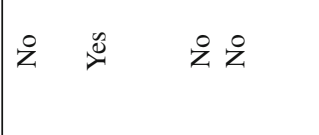 & $\stackrel{\infty}{\infty}$ & $\check{z}$ \\
\hline 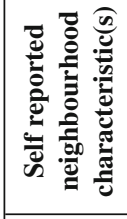 & & & 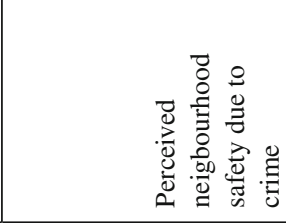 \\
\hline 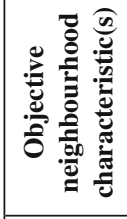 & 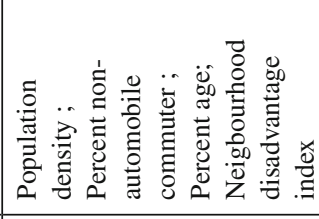 & 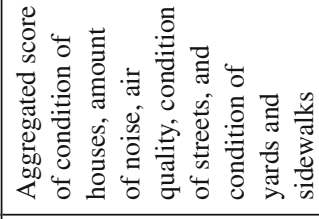 & 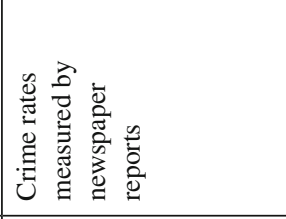 \\
\hline 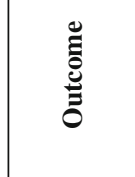 & 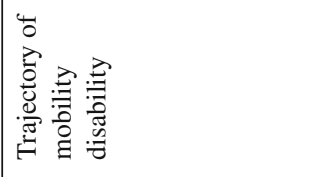 & 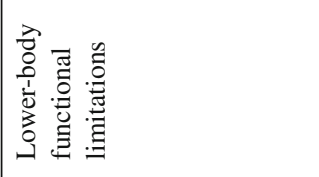 & 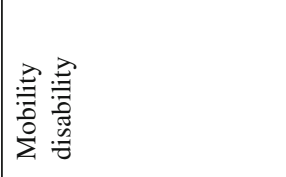 \\
\hline 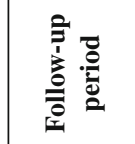 & 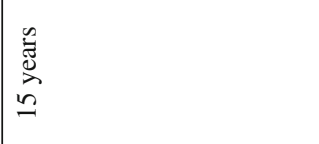 & 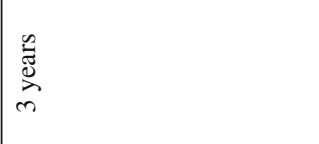 & 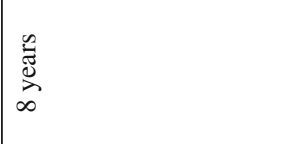 \\
\hline 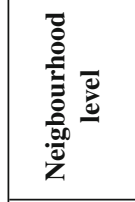 & 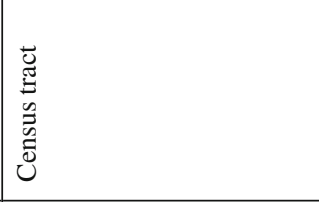 & 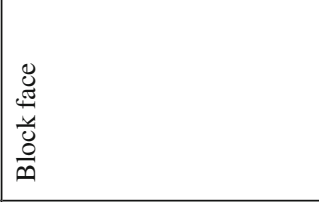 & 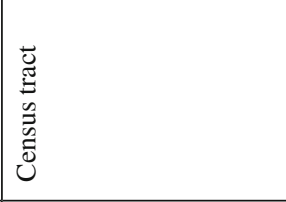 \\
\hline 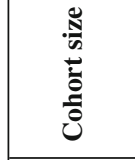 & 鴊 & 总 & $\mid \begin{array}{l}+ \\
\stackrel{\infty}{\infty} \\
\stackrel{\infty}{\sim}\end{array}$ \\
\hline 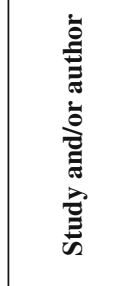 & 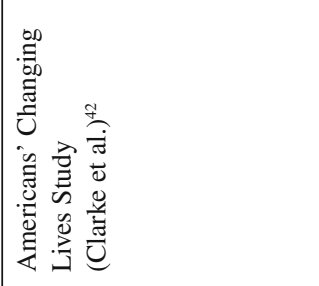 & 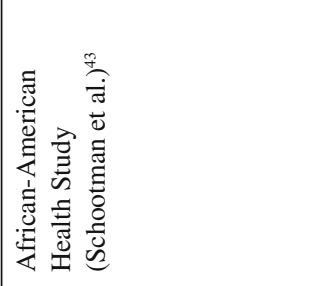 & 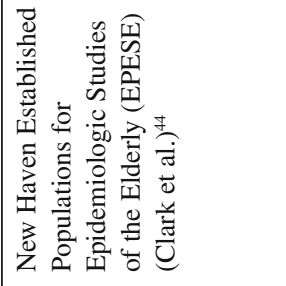 \\
\hline
\end{tabular}


Longitudinal studies are better placed to consider causality, although extended follow-up may be needed. For this reason, we place a heavier emphasis on the evidence generated by prospective research in the discussion below.

Defining and measuring the specific neighbourhood characteristics that may be operating was also a challenge for many studies. While some broad characteristics such as neighbourhood socioeconomic status and residential stability can often be objectively determined from census data, information on other characteristics such as safety, urban decay or social cohesion is rarely routinely available. One commonly used alternative is relying on participant perceptions of neighbourhood characteristics. Yet this may also be problematic since perceptions may reflect characteristics of the individual rather than the environment and may be directly influenced by the outcome of interest. ${ }^{46,47}$ For example, a frail person may be more fearful of their environment or a depressed person may perceive less social support.

At a more general level, neighbourhood definitions varied extensively between studies. While convenient, geographic or administrative definitions may not coincide with the true community within which an older person lives, and large neighbourhoods may mask heterogeneity of both neighbourhood populations and environmental characteristics. Other common limitations included failure to account for possible individuallevel confounders, failure of analysis to account for within neighbourhood clustering, correlations between multiple environmental measures in analysis and inability to account for neighbourhood change between the time of characterizing the neighbourhood and determining a participant's health status or to account for a lag period between time of residence and the development of the outcome.

Despite these methodologic challenges, the evidence for neighbourhood influences on the health of older people is growing. A recent review of the influence of the neighbourhood environment on the health of older adults found 33 studies (of which 25 were cross-sectional) with a positive association in all but three. ${ }^{48} \mathrm{~A}$ recent review of studies examining the association between neighbourhood characteristics and physical activity at all ages found a consistent relationship between walking and a range of physical characteristics, although almost all research was cross-sectional. ${ }^{49}$ A similar review of the impact of the urban environment on mental health identified 45 studies, of which 37 reported positive associations. ${ }^{50}$

The most consistent environmental predictor in the studies identified was neighbourhood socioeconomic status. This was associated with many outcomes in cross-sectional research, even after adjustment for individual characteristics, including depression, ${ }^{51-53}$ physical activity, ${ }^{54,55}$ chronic pain, ${ }^{56}$ 
dental service use, ${ }^{57}$ cognitive function, ${ }^{58,59}$ subclinical cardiovascular disease, ${ }^{60}$ anger, ${ }^{61}$ self-rated health, ${ }^{62,63-66}$ quality of life, ${ }^{67}$ and disability. ${ }^{68-71}$ Other studies failed to find an association..$^{72-74}$

A causative role for neighbourhood disadvantage in these associations is supported by a number of longitudinal studies, which have found similar effects after accounting for individual level characteristics. When 5074 older participants in the Cardiovascular Health Study were followed for eight years, the risk of incident cardiovascular, but not non-cardiovascular, death was increased for participants living in the most disadvantaged neighbourhoods after adjustment for prevalent baseline disease and cardiovascular risk factors. ${ }^{26} \mathrm{~A}$ four to seven year follow-up of progressive chronic kidney disease in 4,735 older participants of the same study found a 50 percent increase in risk for residents of the lowest quartile of neighbourhood socioeconomic status. ${ }^{30}$

When 10,557 elderly Medicare beneficiaries throughout the city of Chicago who had been newly diagnosed and hospitalized for the first time were followed over six years, participants who lived in neighbourhoods with higher socioeconomic status or with a better social environment (defined by independent social survey) had significantly longer survival after disease onset. Myocardial infarction was the primary force driving the associations. ${ }^{75}$

Two year follow-up of the English Longitudinal Study of Ageing (ELSA) found neighbourhood disadvantage was associated with both impaired gait speed and self-reported incident mobility difficulties. ${ }^{31}$ In this short period, 13.6 per 100 residents of disadvantaged neighbourhoods developed incident mobility difficulties compared to 4 in 100 residents in the least disadvantaged neighbourhoods.

A two year follow-up of participants in the New York City Neighbourhood And Mental hEalth Study (NYCNAMES) conducted by one of the authors of this review, found an association between the socioeconomic status of an older person's place of residence and deterioration in symptoms of depression. ${ }^{34}$

When cognitive function was followed over a five year period in 3,050 participants of the Hispanic Established Populations for Epidemiologic Studies of the Elderly, odds of incident cognitive decline decreased as a function of neighbourhood percentage of Mexican American residents and increased with neighbourhood economic disadvantage. ${ }^{35}$ The North Staffordshire Osteoarthritis Project (NorStOP) sent individuals aged 50 and over baseline and three year questionnaires. Nineteen percent of the 3,644 people without pain interference at baseline reported it at follow-up and participants living in areas of high health deprivation had an increased risk of developing pain interference. ${ }^{32}$ 
Educational levels are often used as surrogate measures of socioeconomic status. In a longitudinal study of mortality in the entire Norwegian population, total mortality was increased in residents of municipalities with low average education levels, but only among men who had lived for over ten years in the same place. ${ }^{36}$

However, not all longitudinal studies of neighbourhood disadvantage identify an association. When 2,632 non-institutionalized participants in the Study of Assets and Health Dynamics Among the Oldest Old (AHEAD), were followed over three waves, an observed association between neighbourhood-level socioeconomic disadvantage and change in depressive symptoms was lost after adjustment for individual-level characteristics. ${ }^{37}$ A study of six medical conditions and survival over seven years in 3,050 older Mexican Americans found morbidity and mortality were lowest in neighbourhoods with high proportions of Mexican Americans and greatest in neighbourhoods where Mexican Americans are most integrated with non-Hispanics. This sociocultural advantage outweighed any disadvantages conferred by the high neighbourhood poverty. ${ }^{27}$

It is also worth noting a provocative study of 8,197 individuals that was excluded from our review because the cohort was not limited to older ages. Participants were initially surveyed between 1979 and 1990, and followed until 2002. Death rates among participants of low socioeconomic status were highest in the least disadvantaged neighborhoods, lower in moderately disadvantaged neighborhoods, and lowest in the most disadvantaged neighborhoods. The authors concluded that individuals of low socioeconomic status may not benefit from the higher quality of resources and knowledge generally associated with less disadvantaged neighbourhoods. ${ }^{76}$

Neighbourhood socioeconomic disadvantage may influence health through a variety of different mechanisms. None of the positive studies reviewed were able to examine pathways in enough detail to clarify how any observed associations may be mediated. However, a large number of cross-sectional studies have explored the influence of specific neighbourhood characteristics. Positive findings include associations between neighbourhood psychosocial hazards and cardiovascular disease ${ }^{77}$; neighbourhood walkability and physical activity ${ }^{54,78,79}$ or lowered risk of depression ${ }^{51}$; perceived neighbourhood safety and activity ${ }^{80,81}$; physical activity and social cohesion ${ }^{82}$ or number of neighbourhood destinations ${ }^{83}$; street connectivity and lower risk of obesity ${ }^{84}$; living in areas of high religious affiliation and reduced mortality ${ }^{85}$; and structural context and self rated health. ${ }^{64}$ Other studies had negative or uncertain findings. ${ }^{64,86}$ It should also be noted that in many of the positive studies, multiple environmental 
characteristics were assessed and positive associations were only identified for some of these factors.

A range of specific built environment characteristics has been examined in longitudinal research. For example, living in areas with better neighbourhood resources, defined by a combined score for physical activity and health foods, was found to be associated with reduced incidence of type 2 diabetes during a five year follow-up of 2,285 participants in the Multi-Ethnic Study of Atherosclerosis. ${ }^{38}$

The absence of similar characteristics have been found to be associated with obesity and lower levels of physical activity, both of which increase risk for diabetes and cardiovascular disease. When 303 older adults were followed in four waves over one year, there was a general downward trajectory of walking over time. However, neighbourhoods with safe walking environments and access to physical activity facilities had lower rates than less favorable neighbourhoods. ${ }^{28}$ When weight and waist circumferences of 1,145 residents of Portland, Oregon, were assessed at baseline and after one year, mean weight and mean waist circumference increased. Increases were greater among residents of neighbourhoods with a high density of fast food outlets (measured using Geographic Information Systems) and high-walkability neighbourhoods were associated with decreases in weight and in waist circumference among residents who increased their levels of vigorous physical activity. ${ }^{39}$

The same study found that over the observation period, there was a small increase in both mean systolic and mean diastolic blood pressures. However, residing in highly walkable neighbourhoods was associated with decreases in systolic and diastolic blood pressure, while an observed negative association of fast food restaurants on blood pressure was diminished among highly walkable neighbourhoods. ${ }^{40}$

There is also longitudinal evidence to support cross-sectional findings suggesting that fear of crime, street design that favors motorized transportation and neighbourhood decay may adversely influence health outcomes.

A 15 year follow-up of a nationally representative sample of Americans found that trajectories of mobility disability were worse for older adults (age 75 and over) living in neighbourhoods characterized by more motorized travel. ${ }^{42}$ When 563 subjects of the African-American Health Study received in-home evaluations at baseline and three years later, persons who lived in poor neighbourhood conditions (assessed at baseline by the interviewer) were more likely to develop two or more lower body functional limitations. ${ }^{43}$ 
The New Haven Established Populations for Epidemiologic Studies of the Elderly (EPESE) followed 1,884 participants without mobility disability for eight years. Participants' baseline perceptions of lack of neighbourhood safety due to crime were associated with increased risk of subsequent incident mobility disability, but only among participants whose incomes were below the federal poverty line. No association was found with living in neighbourhoods with high crime rates when measured by newspaper reports. ${ }^{44}$ This study raises the interesting issue of the relative importance of resident perceptions of their neighbourhood and more objective external assessment.

The Alameda County Study questioned 883 older and functionally healthy participants in 1994 and 1995. Risk of self-reported functional loss among participants who had not reported it at baseline was higher at follow-up among those who had previously reported multiple-problem neighbourhoods. Neighbourhood problems associated with the largest increase in risk were excessive noise, inadequate lighting, and heavy traffic. $^{87}$

Housing design too, may influence health and social well-being. A population based sample of 273 disadvantaged Hispanic elders (70-100 years of age) in a socioeconomically disadvantaged Hispanic neighbourhood received three annual assessments of social support, psychological distress, and physical functioning. Architectural features of the built environment theorized to facilitate direct observations and interactions (e.g., porches, stoops) had a significant direct relationship with elders' physical functioning as measured three years later, and an indirect relationship through social support and psychological distress. ${ }^{33}$

Finally, one study that highlights the risk of selection biases and other methodological challenges of neighbourhood research is the Harvard Alumni Study. When initially assessed cross-sectionally, urban sprawl at a county level was found to be associated with less physical activity in male participants. However, when the association was studied longitudinally in 3,448 participants and change in exposure to sprawl was considered for participants changing residence, no association was found. The authors concluded that "these findings suggest that the cross-sectional results may reflect self-selection, rather than indicating that....urban sprawl...increases physical activity. However, the longitudinal findings were limited by small numbers..."41 They were also limited by the large area level at which sprawl was defined which may serve to mask significant heterogeneity. 


\section{URBAN INITIATIVES TO FOSTER HEALTHY AGEING}

In parallel with this body of research, a number of interventions have been developed over recent years to create urban environments that assist older people to remain healthy and engaged in their community.

In the United States, "Partners for Livable Communities" was established in 1977 to improve the livability of communities by promoting quality of life, economic development, and social equity. More recently, the programme has promoted the concept of "ageing in place" and in 2007 published "the Aging in Place Technical Assistance Guide" and "A Blueprint for Action: Developing a Livable Community for All Ages" ${ }^{88,89}$ These identify seven key issues for enabling older people to age in place: housing; planning and zoning; transportation; health and supportive services; cultures and lifelong learning; public safety; and civic engagement opportunities. AARP, a nonprofit, nonpartisan membership organization in the US that helps people 50 and over improve the quality of their lives, has followed a similar approach for its own Livable Communities programme, which places a particular emphasis on community engagement and defines a livable community as one that "has affordable and appropriate housing, supportive community features and services, and adequate mobility options, which together facilitate personal independence and the engagement of residents in civic and social life"..${ }^{90}$ Both of these approaches are consistent with a 2004 report from the US National Council on Disability (NCD) on "Livable Communities for Adults with Disabilities".91

The AdvantAge Initiative led by the Centre for Home Care Policy and Research, Visiting Nurse Association of New York and supported by a number of private foundations, takes a community development approach to create communities that are prepared to meet the needs and nurture the aspirations of older adults. At the heart of the AdvantAge Initiative is a comprehensive survey of community-residing older adults designed to complement the "topdown" perspectives of institutions and professionals, and challenge organizational and individual assumptions. This engages older people in a dialogue about ageing issues, and builds support for plans of action. The survey focuses on four key areas: Basic needs for housing and security, maintenance of physical and mental health, independence for the frail, disabled, and homebound, and opportunities for social and civic engagement. ${ }^{92}$

Similar projects have been undertaken in urban environments in other countries, including the City of Calgary's Elder Friendly Community, ${ }^{93}$ the Valuing Older People Partnership in Manchester in the United Kingdom, ${ }^{94}$ and the Canberra Plan, an Age-friendly City project in Australia. ${ }^{95}$ 
Two international programmes on ageing and the urban environment have also been established. Healthy ageing has been identified as one of three core themes in the Phase IV (2003-2008) of the World Health Organization's Healthy Cities Network, with the goal of generating strong local political commitment and of introducing policies and planning processes that will ensure a holistic and well-balanced approach to older people's needs for health development and care. ${ }^{96}$ Cities develop a profile of the health of older people to inform strategy development to help achieve this goal.

The World Health Organization has also developed a programme specifically on Age-friendly Environments ${ }^{97}$ Defining an Age-friendly City as one that "encourages active ageing by optimizing opportunities for health, participation and security in order to enhance quality of life as people age", the programme commenced in 2006 with a project to subjectively identify the characteristics of the urban environment that might foster this goal. Academic partners in 33 cities around the world asked older people in focus groups to describe the advantages and barriers they experienced in eight areas of city living. In most cities, the reports from older people were complemented by focus groups of caregivers and service providers. The eight domains considered included features of a city's physical environment that may have an influence on personal mobility, safety from injury, security from crime, health behaviour and social participation; different aspects of the social environment and of culture that may affect participation and mental well-being; characteristics that foster communication and access to information; and community support and health services. The WHO Global Network of Age-friendly Cities was established in late 2009, and is designed to link participating municipalities, foster evaluation of age-friendly initiatives and provide technical support. Unlike the academic focus of the original project, the Network focus is on implementation, and a requirement for participation in the Network is that the Municipality formally commits to a process of continual improvement. At the time of writing, a number of cities had begun to participate in the Network including 34 French cities through their membership with a partner programme "Bien Vieillir, Vivre Ensemble".

Unfortunately, to date, there has been little opportunity to evaluate the impact of these diverse initiatives. 


\section{CONCLUSION}

It has long been argued that the health of an older person is intimately entwined with the physical, social and economic environment in which they live..$^{22}$ Over the past decade, epidemiologic evidence to support this position has grown, although most research has been cross-sectional. However, in the last two years alone, at least 13 new longitudinal studies examining these issues have been reported, with ten having positive findings consistent with previous cross-sectional research. Unfortunately, few of these studies can yet point to specific pathways that may be amenable to intervention.

Concurrent with this research, a number of sizable programmes have been developed to redesign the urban environment to be more supportive of older people. These have often arisen from a background of clinical and community care, or of urban design. To date, little research has been undertaken of their impact on the health and lives of older people.

While the potential for improvements in the urban environment to foster the health, social engagement and productivity of older people appears large, the investment required to make these changes is also considerable. To ensure this investment is put to best use, it is crucial that the policies and interventions that are adopted are subject to rigorous evaluation. This will not be easy, since it will need to account for many confounding factors and to distinguish between intervention effect and selection biases. However, rigorous evaluation can not only confirm the impact of these approaches and guide future initiatives in this area, but it can also help answer fundamental questions about the relationship between the urban environment and the health of older people.

In the meantime, current theoretical models, and the available epidemiologic evidence, appear to justify the directions being followed by these urban initiatives. Many are also consistent with broader public health strategies on disability.

A number of approaches seem justifiable. These include strategies to foster the ongoing social engagement of older people through improving access to buildings and public transport, improving walkability, creating destinations that encourage older people to leave their homes, strengthening intergenerational links and developing innovative technology such as webbased networking and videoconferencing. Other interventions worth considering include reducing crime and improving urban safety, improving housing design and strengthening neighbourhood social resources. But these are just a few examples of a diverse array that span both the physical and social environments of an older person and that may be 
neighbourhood specific. Policy makers will need to take account of the local environment and the concerns of older residents.

Another obvious need is for a unifying theoretical model that can underpin future research in this field and guide the development of future interventions. This needs to span both ecological perspectives of ageing and broader social theory, and to suggest mechanisms by which environmental characteristics may exert their effect.

If the impact of current strategies can be confirmed, these approaches offer a satisfyingly equitable approach to foster the health of older people. Ensuring that an older person, regardless of their individual socioeconomic status or background, lives in an environment that facilitates healthy behaviours and social engagement, goes some way to overcoming the health disparities that are widely evident in this age group.

Conflicts of Interest: None declared.

\section{REFERENCES}

1. UNDESA. World economic and social survey 2007: Development in an ageing world. United Nations Department of Social and Economic Affairs; 2007.

2. Sikken, B, Davis, N, Hayashi, C, and Olkkonen, H. The future of pensions and healthcare in a rapidly ageing world. Geneva: World Economic Forum; 2009.

3. United Nations. World population prospects: The 2008 revision population database. United Nations Population Division; 2010.

4. Diez Roux AV. Multilevel analysis in public health research. Annu Rev Public Health. 2000;21:171-92.

5. Diez Roux AV. The examination of neighborhood effects on health: Conceptual and methodological issues related to the presence of multiple levels of organization. In: Berkman L, editor. Neighborhoods and health. New York (NY): Oxford University Press; 2003. p. 45-64.

6. Bowling A, Stafford M. How do objective and subjective assessments of neighbourhood influence social and physical functioning in older age? Findings from a British survey of ageing. Soc Sci Med. 2007;64:2533-49.

7. UNFPA. State of the world population 2007: Unleashing the potential of urban growth. New York, (NY): United Nations Population Fund; 2007.

8. McLeod JD, Kessler RC. Socio-economic status differences in vulnerability to undesirable life events. J Health Soc Behav. 1990;31:162-72.

9. Ross CE, Mirowsky J. Neighbourhood disadvantage, disorder, and health. J Health Soc Behav. 2001;42:258-76.

10. Schulz AJ, Israel BA, Zenk SN Parker EA, Lichtenstein R, Shellman-Weir S, et al. Psychosocial stress and social support as mediators of relationships between income, length of residence and depressive symptoms among African American women on Detroit's eastside. Soc Sci Med. 2006;62:510-22. 
11. Sampson RJ, Raudenbush SW, Earls F. Neighborhoods and violent crime: A multilevel study of collective efficacy. Science. 1997;277:918-24. 1997.

12. Sampson RJ, Morenoff JD, Gannon-Rowley T. Assessing "neighborhood effects": Social processes and new directions in research. Ann Rev Soc. 2002;28:443-78.

13. Lin N, Ye XL, Ensel WM. Social support and depressed mood: A structural analysis J Health Soc Behav. 1999;40:344-59.

14. Ostir GV, Eschbach K, Markides KS, Goodwin JS. Neighbourhood composition and depressive symptoms among older Mexican Americans. J Epidemiol Community Health. 2003;57:987-92.

15. Wheaton B. Stress, personal coping resources, and psychiatric symptoms: An investigation of interactive models. J Health Soc Behav. 1983:24:208-29.

16. Fitzpatrick KM, LaGory M. "Placing" health in an urban sociology: cities as mosaics of risk and protection. City Community. 2003;2:33-46.

17. Wheaton B. Models for the stress-buffering functions of coping resources. J Health Soc Behav. 1985;26:352-64.

18. Booth ML, Owen N, Bauman A, Clavisi O, Leslie E. Social-cognitive and perceived environment influences associated with physical activity in older Australians. Prev Med. 2000;31:15-22.

19. King AC, Castro C, Wilcox S, Eyler AA, Sallis JF, Brownson RC. Personal and environmental factors associated with physical inactivity among different racial-ethnic groups of U.S. middle-aged and older-aged women. Health Psychol. 2000;19:354-64.

20. King WC, Belle SH, Brach JS, Simkin-Silverman LR, Soska T, Kriska AM. Objective measures of neighborhood environment and physical activity in older women. Am J Prev Med. 2005;28:461-9.

21. Wilcox S, Bopp M, Oberrecht L, Kammermann SK, McElmurray CT. Psychosocial and perceived environmental correlates of physical activity in rural and older african american and white women. J Gerontol B Psychol Sci Soc Sci. 2003;58:329-37.

22. Lawton MP, Nahemow L. Ecology and the aging process. In: Eisdorfer C, Nahemow L, editors. The psychology of adult development and aging. Washington (DC): American Psychology Association; 1973. p. 464-88.

23. Alley D, Liebig P, Pynoos J, Banerjee T, Choi I. H. Creating elder-friendly communities: Preparations for an aging society. J Gerontol Soc Work. 2007;49:1-18.

24. Keller IM, Kalache A. Promoting healthy aging in cities: The Healthy Cities project in Europe. J Cross Cult Gerontol. 1997;12:287-98.

25. Balfour J L, Kaplan, GA. Neighborhood environment and loss of physical function in older adults: evidence from the Alameda County Study. Am J Epidemiol. 2002;155:507-15.

26. Diez Roux AV, Borrell LN, Haan M, Jackson SA, Schultz R. Neighbourhood environments and mortality in an elderly cohort: results from the cardiovascular health study. J Epidemiol Community Health. 2004;58:917-23. 
27. Eschbach K, Ostir GV, Patel KV, Markides KS, Goodwin, JS. Neighborhood context and mortality among older Mexican Americans: Is there a barrio advantage? Am J Public Health. 2004;94:1807-12.

28. Li F, Fisher J, Brownson RC. A multilevel analysis of change in neighborhood walking activity in older adults. J Aging Phys Act. 2005;13:145-59.

29. Wen M, Christakis NA. Neighborhood effects on posthospitalization mortality: A population-based cohort study of the elderly in Chicago. Health Serv Res. 2005;40:1108-27.

30. Merkin SS, Roux AV, Coresh J, Fried LF, Jackson SA, Powe NR. Individual and neighborhood socioeconomic status and progressive chronic kidney disease in an elderly population: The Cardiovascular Health Study. Soc Sci Med. 2007;65:809-21.

31. Lang IA, Llewellyn DJ, Langa KM, Wallace RB, Melzer D. Neighbourhood deprivation and incident mobility disability in older adults. Age Ageing. 2008;37:403-10.

32. Jordan KP, Thomas E, Peat G, Wilkie R, Croft P. Social risks for disabling pain in older people: A prospective study of individual and area characteristics. Pain. 2008;137:652-61.

33. Brown SC, Mason CA, Perrino T, Lombard JL, Martinez F, Plater-Zyberk E, et al. Built environment and physical functioning in Hispanic elders: The role of "eyes on the street". Environ Health Perspect. 2008;116:1300-7.

34. Beard JR, Cerda M, Blaney S, Ahern J, Vlahov D, Galea S. Neighborhood characteristics and change in depressive symptoms among older residents of New York City. Am J Public Health. 2009;99:1308-14.

35. Sheffield KM, Peek MK. Neighborhood context and cognitive decline in older Mexican Americans: Results from the Hispanic Established Populations for Epidemiologic Studies of the Elderly. Am J Epidemiol. 2009;169:1092-101.

36. Kravdal O. Mortality effects of average education in current and earlier municipality of residence among internal migrants, net of their own education. Soc Sci Med. 2009;69:1484-92.

37. Wight RG, Cummings JR, Karlamangla AS, Aneshensel CS. Urban neighborhood context and change in depressive symptoms in late life. J Gerontol B Psychol Sci Soc Sci. 2009;64:247-51.

38. Auchincloss AH, Diez Roux AV, Mujahid MS, Shen M, Bertoni AG, Carnethon MR. Neighborhood resources for physical activity and healthy foods and incidence of type 2 diabetes mellitus: The Multi-Ethnic study of Atherosclerosis. Arch Int Med. 2009;169:1698-704.

39. Li F, Harmer P, Cardinal BJ, Bosworth M, Johnson-Shelton D, Moore JM, et al. Built environment and 1-year change in weight and waist circumference in middle-aged and older adults: Portland Neighborhood Environment and Health Study. Am J Epidemiol. 2009;169:401-8.

40. Li F, Harmer P, Cardinal BJ, Vongjaturapat N. Built environment and changes in blood pressure in middle aged and older adults. Prev Med. 2009;48:237-41.

41. Lee IM, Ewing R, Sesso HD. The built environment and physical activity levels: The Harvard Alumni Health Study. Am J Prev Med. 2009;37:293-8. 
42. Clarke P, Ailshire JA, Lantz P. Urban built environments and trajectories of mobility disability: Findings from a national sample of community-dwelling American adults (1986-2001). Soc Sci Med. 2009;69:964-70.

43. Schootman M, Andresen EM, Wolinsky FD, Malmstrom TK, Miller JP, Miller DK. Neighborhood conditions and risk of incident lower-body functional limitations among middle-aged African Americans. Am J Epidemiol. 2006;163:450-8.

44. Clark CR, Kawachi I, Ryan L, Ertel K, Fay ME, Berkman LF. Perceived neighborhood safety and incident mobility disability among elders: The hazards of poverty. BMC Public Health. 2009;9:162.

45. Oakes JM. The (mis)estimation of neighborhood effects: Causal inference for a practicable social epidemiology. Soc Sci Med. 2004;58:1929-52.

46. Leslie E. Cerin E. Are perceptions of the local environment related to neighbourhood satisfaction and mental health in adults? Prev Med. 2008;47:273-8.

47. Michael Y, Beard T, Choi D, Farquhar S, Carlson N. Measuring the influence of built neighborhood environments on walking in older adults. J Aging Phys Act. 2006;14:302-12.

48. Yen IH, Michael YL, Perdue L. Neighborhood environment in studies of health of older adults: A systematic review. Am J Prev Med. 2009;37:455-63.

49. Saelens BE, Handy SL. Built environment correlates of walking: a review. Med Sci Sports Exerc. 2008;40:S550-66.

50. Mair C, Diez Roux A, Galea S. Are Neighborhood characteristics associated with depressive symptoms? A review of evidence. J Epidemiol Community Health. 2008;62:940-6.

51. Berke EM, Gottlieb LM, Moudon AV, Larson EB. Protective association between neighborhood walkability and depression in older men. J Am Geriatr Soc. 2007;55:526-33.

52. Aneshensel CS, Wight RG, Miller-Martinez D, Botticello AL, Karlamangla AS, Seeman TE. Urban neighborhoods and depressive symptoms among older adults. J Gerontol B Psychol Sci Soc Sci. 2007;62:S52-9.

53. Kubzansky LD, Subramanian SV, Kawachi I, Fay ME, Soobader MJ, Berkman LF. Neighborhood contextual influences on depressive symptoms in the elderly. Am J Epidemiol. 2005;162:253-60.

54. Berke EM, Koepsell TD, Moudon AV, Hoskins RE, Larson EB. Association of the built environment with physical activity and obesity in older persons. Am J Public Health. 2007;97:486-92.

55. Hillsdon M, Lawlor DA, Ebrahim S, Morris JN. Physical activity in older women: Associations with area deprivation and with socioeconomic position over the life course: Observations in the British Women's Heart and Health Study. J Epidemiol Community Health. 2008;62:344-50.

56. Fuentes M, Hart-Johnson T, Green CR. The association among neighborhood socioeconomic status, race and chronic pain in black and white older adults. J Natl Med Assoc. 2007;99:1160-9. 
57. Lang IA, Gibbs SJ, Steel N, Melzer D. Neighbourhood deprivation and dental service use: A cross-sectional analysis of older people in England. J Public Health. 2008;30:472-8.

58. Lang IA, Llewellyn DJ, Langa KM, Wallace RB, Huppert FA, Melzer D. Neighborhood deprivation, individual socioeconomic status, and cognitive function in older people: Analyses from the English Longitudinal Study of Ageing. J Am Geriatr Soc. 2008;56:191-8.

59. Wight RG, Aneshensel CS, Miller-Martinez D, Botticello A. L, Cummings JR, Karlamangla AS, Seeman TE. Urban neighborhood context, educational attainment, and cognitive function among older adults. Am J Epidemiol. 2006;163:1071-8.

60. Nordstrom CK, Diez Roux AV, Jackson SA, Gardin JM. The association of personal and neighborhood socioeconomic indicators with subclinical cardiovascular disease in an elderly cohort. The cardiovascular health study. Soc Sci Med. 2004;59:2139-47.

61. Schieman S, Pearlin LI, Meersman SC. Neighborhood disadvantage and anger among older adults: Social comparisons as effect modifiers. J Health Soc Behav. 2006;47:156-72.

62. Wight RG, Cummings JR, Miller-Martinez D, Karlamangla AS, Seeman TE, Aneshensel CS. A multilevel analysis of urban neighborhood socioeconomic disadvantage and health in late life. Soc Sci Med. 2008;66:862-72.

63. Cagney KA, Browning CR, Wen M. Racial disparities in self-rated health at older ages: What difference does the neighborhood make? J Gerontol B Psychol Sci Soc Sci. 2005;60:S181-90.

64. Subramanian SV, Kubzansky L, Berkman L, Fay M, Kawachi I. Neighborhood effects on the self-rated health of elders: Uncovering the relative importance of structural and service-related neighborhood environments. J Gerontol B Psychol Sci Soc Sci. 2006;61:S153-60.

65. Robert SA Ruel E. Racial segregation and health disparities between Black and White older adults. J Gerontol B Psychol Sci Soc Sci. 2006;61:S203-11.

66. Patel KV, Eschbach K, Rudkin LL, Peek MK, Markides KS. Neighborhood context and self-rated health in older Mexican Americans. Ann Epidemiol. 2003; 13:620-8.

67. Breeze E, Jones DA, Wilkinson P, Bulpitt CJ, Grundy C, Latif AM, Fletcher AE. Area deprivation, social class, and quality of life among people aged 75 years and over in Britain. Int J Epidemiol. 2005;34:276-83.

68. Freedman VA, Grafova IB, Schoeni RF, Rogowski J. Neighborhoods and disability in later life. Soc Sci Med. 2008;66:2253-67.

69. Beard JR, Blaney S, Cerda M, Frye V, Lovasi GS, Ompad D, et al. Neighborhood characteristics and disability in older adults. J Gerontol B Psychol Sci Soc Sci. 2009;64:252-7.

70. Clarke P, George LK. The role of the built environment in the disablement process. Am J Public Health. 2005;95:1933-9. 
71. Schmitz N, Nitka D, Gariepy G, Malla A, Wang J, Boyer R, et al. Association between neighborhood-level deprivation and disability in a community sample of people with diabetes. Diabetes Care. 2009;32:1998-2004.

72. Pikhartova J, Chandola T, Kubinova R, Bobak M, Nicholson A, Pikhart H. Neighbourhood socioeconomic indicators and depressive symptoms in the Czech Republic: A population based study. Int J Public Health. 2009;54:283-93.

73. Hybels CF, Blazer DG, Pieper CF., Burchett BM, Hays JC, Fillenbaum GG, et al. Sociodemographic characteristics of the neighborhood and depressive symptoms in older adults: Using multilevel modeling in geriatric psychiatry. Am J Geriatr Psychiatry. 2006;14:498-506.

74. Walters K, Breeze E, Wilkinson P, Price GM, Bulpitt CJ, Fletcher A. Local area deprivation and urban-rural differences in anxiety and depression among people older than 75 years in Britain. Am J Public Health. 2004;94:1768-74.

75. Wen M, Hawkley LC, Cacioppo JT. Objective and perceived neighborhood environment, individual SES and psychosocial factors, and self-rated health: An analysis of older adults in Cook County, Illinois. Soc Sci Med. 2006;63:2575-90.

76. Winkleby M, Cubbin C, Ahn D. Effect of cross-level interaction between individual and neighborhood socioeconomic status on adult mortality rates. Am J Public Health. 2006;96:2145-53.

77. Augustin T, Glass TA, James BD, Schwartz BS. Neighborhood psychosocial hazards and cardiovascular disease: The Baltimore Memory Study. Am J Public Health 2008;98;1664-70.

78. Li F, Harmer PA, Cardinal BJ, Bosworth M, Acock A, Johnson-Shelton D, Moore JM. Built environment, adiposity, and physical activity in adults aged 50-75. Am J Prev Med. 2008;35:38-46.

79. Li F, Fisher KJ, Brownson RC, Bosworth M. Multilevel modelling of built environment characteristics related to neighbourhood walking activity in older adults. J Epidemiol Community Health. 2005;59:558-64.

80. Booth ML, Owen N, Bauman A, Clavisi O, Leslie E. Social-cognitive and perceived environment influences associated with physical activity in older Australians. Prev Med. 2000;31:15-22.

81. Mendes de Leon CF, Cagney KA, Bienias JL, Barnes LL, Skarupski KA, Scherr PA, Evans DA. Neighborhood social cohesion and disorder in relation to walking in community-dwelling older adults: A multilevel analysis. J Aging Health. 2009;21:155-71.

82. Fisher KJ, Li F, Michael Y, Cleveland M. Neighborhood-level influences on physical activity among older adults: A multilevel analysis. J Aging Phys Act. 2004; $12: 45-63$.

83. Gauvin L, Riva M, Barnett T, Richard L, Craig CL, Spivock M, et al. Association between neighborhood active living potential and walking. Am J Epidemiol. 2008;167;944-53. 
84. Grafova IB, Freedman VA, Kumar R, Rogowski J. Neighborhoods and obesity in later life.[Erratum appears in Am J Public Health. 2009;99:392]. Am J Public Health. 2008;98:2065-71.

85. Jaffe DH, Eisenbach Z, Neumark YD, Manor O. Does living in a religiously affiliated neighborhood lower mortality? Ann Epidemiol. 2005;15:804-10.

86. Nagel CL, Carlson NE, Bosworth M, Michael YL. The relation between neighborhood built environment and walking activity among older adults. Am J Epidemiol 2008;168:461-8.

87. Balfour JL, Kaplan GA. Neighborhood environment and loss of physical function in older adults: Evidence from the Alameda County Study. Am J Epidemiol 2002;155:507-15.

88. A Blueprint for Action: Developing Livable Communities for All Ages. Partners for Livable Communities (Partners) and the National Association of Area Agencies on Aging. 2010.

89. Partners for Livable Communities. Aging in Place Technical Assistance Guide. Washington, (DC): Partners for Livable Communities; 2007.

90. Kochera A, Straight A, Guterbok, T. Beyond 50.05: A report to the nation on Livable Communities Creating Environments for Successful Aging. 2010. Washington (DC): AARP.

91. National Council on Disability. Livable Communities for Adults with Disabilities. Washington (DC): National Council on Disability; 2004.

92. The AdvantAGE Initiative. 2010. Available from URL: http://www.vnsny.org/ advantage/ (Accessed 5 April 2011).

93. Austin C, Flux D, Ghali L, Hartley D, Holinda D, McClelland R, et al. A place to call home: Final report of the Elder Friendly Communities Project. City of Calgary (Canada): 2001.

94. Valuing Older People. Manchester (UK): Manchester City Council; 2010.

95. ACT Strategic Plan for Positive Ageing 2010- 2014: Towards an Age-Friendly City. Canberra (Australia): ACT Government; 2010.

96. Healthy cities and urban governance. 2010.

97. WHO. WHO Age-Friendly Environments Programme. Geneva: World Health Organization; 2010. 